Solidarity: The Role of Non-Black People of Color in Promoting Racial Equity

Department of Psychology

Western Michigan University

Contact Author: Anita Li

Address: Department of Psychology

Western Michigan University

Kalamazoo, Michigan 49008

Phone: $269-387-4329$

Fax: 269-387-4450

Email: anita.li@wmich.edu

Author's note: The author has no conflict of interest to declare. 


\begin{abstract}
Multicultural behavior analysts must stand together to address the issues of systemic racism collectively, show solidarity, and support Black lives. This paper discusses the role of culturally and linguistically diverse behavior analysts, mechanisms underlying barriers to showing solidarity, and mechanisms required for cultural evolution to promote a compassionate and nurturing approach to racial equity. It is critical that non-Black people of color actively participate in antiracist advocacy to show solidarity to the Black Lives Matter movement.
\end{abstract}

Keywords: cooperation, cultural evolution, diversity, equity, systemic racism 
This manuscript is being published on an expedited basis, as part of a series of emergency publications designed to help practitioners of applied behavior analysis take immediate action to address police brutality and systemic racism. The journal would like to especially thank Jovonnie Esquierdo-Leal and Dr. Shameka McCammon for their insightful and expeditious reviews of this manuscript. The views and strategies suggested by the articles in this series do not represent the positions of the Association for Behavior Analysis, International or Springer Nature.

Guest Editor, Denisha Gingles 


\section{Solidarity: The Role of Non-Black People of Color in Promoting Racial Equity}

Not long after the publication of the Special Issue on Diversity and Inclusion in Behavior Analysis in Practice (Zarcone et al., 2019), we witnessed the culmination of systemic racism unfold. George Floyd was killed by a white police officer kneeling on his neck in an eightminute prone restraint. Breonna Taylor was fatally shot in her home by police looking for a suspect who was already in custody. Tony McDade was shot to death by police officers, without warning or de-escalation attempts (Thompson, 2020). The Black Lives Matter movement began in 2013, with the acquittal of George Zimmerman for the murder of Black teenager Trayvon Martin, which spurred national attention, resulting in campaigns and protests (Day, 2015). The murders of Floyd and Taylor in 2020 resulted in worldwide protests and recognition of the public health crisis of disproportionate Black deaths as a result of police brutality (Booker, 2020; Fuller, 2020; Watkins, 2020). Serendipitously, yet prior to the aforementioned events, Matsuda and colleagues (2020) published a review of behavior analytic articles focused on reducing racism, which revealed that zero articles met their inclusionary criteria. This is a significant indicator that the field of behavior analysis requires thorough and mindful attention to conceptualize and develop strategies to mitigate issues related to racism.

There have been several discussion pieces published to promote cultural understanding and humility geared towards practice, such as self-reflection, developing awareness, and reiterating the ethical obligations in working with clients of diverse backgrounds (e.g., Dennison et al., 2019; Fong et al., 2016; Fong et al., 2017; Kornack et al., 2019; Wright, 2019). These are important contributions that promote the advocacy and considerations of culturally diverse clients; however, the central tenant is geared towards educating white practitioners, understandably so as the fields of behavior analysis, education, and psychology at large are 
predominantly white (Dennison et al., 2019; Lin et al., 2018). Fazil et al. (2004) suggest that the advocacy movement has been mainly a "white" phenomenon, resulting in more Westernized concepts of advocacy. Advocacy is a broad construct but usually defined in the context of promoting social justice (of fairness in support, opportunities, and privileges within a society) in disadvantaged groups (Bowes \& Sims, 2005). Bowes \& Sim (2005) also indicate "the development of advocacy as a public 'good' enshrined in policy has not, in their view, been informed by the views and experiences of BME [Black and minority ethnic] communities." As such, members of ethnic and racial groups may be minimized in their participation of individual and collective social responsibility (Astramovich \& Harris, 2007).

Both allyship and contributors to systemic racism, especially in the context of injustice and mistreatment of Black people, are not limited to white individuals. Systemic racism is the large-scale and inescapable hierarchical system of oppression devised by white people and specifically directed at minority racial and ethnic groups (Feagin, 2006). As such, Black, Indigenous, people of color (BIPOC) suffer disproportionately due to inequities created by white people with relative social power, thus resulting in a system where BIPOC are disadvantaged in both social and public policy as a result of racist framing, ideology, attitudes, and discriminatory habits and actions. Due to assimilation, people of color can also engage in the same racist ideology (e.g. non-Black people of color opposing the Black Lives Matter movement). The purpose of this paper is to invoke introspection and promote solidarity-aligned behaviors for non-Black ethnic and racial people of color within the field of applied behavior analysis and facilitate a cultural evolution to reduce racism and prejudice towards Black individuals.

Cultural evolution may imply competition as a result of selection; however, cooperation is needed for evolution to construct new levels of organization (Nowak, 2006). Wilson (2007) 
proposes three distinct characteristics of human evolution: cognition, culture, and cooperation, where cognition and culture only emerge as a result of cooperation first. Therefore, to build an antiracist culture, it is critical that all members within that culture begin to cooperate with one another by engaging in acts of solidarity. The importance of demonstrating solidarity is to unify and ameliorate collective suffering. Solidarity is defined as "unity (as of a group or class) that produces or is based on common interests, objectives, and standards" (Merriam-Webster, n.d.). What is a display of solidarity? Overt actions that challenge (and in some cases, punish) preexisting racial attitudes, model antiracist verbal behavior, and demonstrate equivalences between Black and non-Black people of color injustices. As Matsuda et al. (2020) reviewed, implicit racial bias persists as a result of longer prior social learning histories. Therefore, changing attitudes and perceptions of adults may be harder to measure and achieve on an individual basis, but engaging in specific overt antiracist actions also help model appropriate and desired antiracist behaviors more pragmatically. Antiracism is not the absence of racist behaviors, but the ideas and behaviors that actively promote racial equity (Kendi, 2019).

\section{Anti-Black Attitudes in Culturally Diverse Households}

One way to engage in solidarity-aligned behaviors is to consider and change verbal behavior. Linguistically diverse individuals should also consider their verbal behavior in both English and their native language. In Cantonese (a dialect of Mandarin Chinese), the term 黑鬼 (hak gwei) is commonly used to refer to Black people. This loosely translates to "black ghost." Yet, the term 黑人(hak yun) literally means “Black person” but isn't used as often. Some attribute this due to 黑人(hak yun) is more formal-sounding, whereas 黑鬼 (hak gwei) is more colloquial. Inherently, this subtle choice of language (even implicitly) prevents solidarity to support Black members. Participating in one's native community, whether in-person or online, 
can help provide discussion, insight, and resources to address race equity within one's community. Behavior analysts of linguistically diverse backgrounds should facilitate these discussions in both English-speaking and non-English speaking communities. Fluent native speakers can provide translations and guidance on having difficult conversations with nonEnglish speaking family members and bridging generational and cultural gaps.

The truth is that anti-Black rhetoric and attitudes continue to be prevalent within nonBlack people of color and also affect intersecting racial and ethnic groups, like Afro-Latinx (Wade, 2006). The anti-Black ideas, thoughts, and actions within respective cultures interfere with the overarching goal of solidarity. Addressing concerns with one's families, friends, and community can facilitate a cultural evolution. Recently, there have been calls in the media to address these issues within one's own racial group (Acevado, 2020; Iyer, 2020; Meraji, 2016) due to the silence or even opposition of the Black Lives Matter movement from non-Black people of color groups. There are two possible behavioral interpretations for this divisibility: 1) some non-Black people of color living in America may have assimilated and adopted the underlying white-dominant attitudes via imitation and reinforcement, and 2) the ethnic or racial group had to deal with their own injustices and mistreatment as a racially oppressed group in America. For example, many Chinese Americans were mistreated and discriminated against due to the COVID-19 pandemic (BBC News, 2020). Harmful rhetoric of referring to COVID-19 as the "Chinese virus" and spreading rumors that the Chinese government manufactured the virus has resulted in harming Chinese-owned businesses and Chinese Americans being targeted and physically harmed. Another example is related to the demonization and mistreatment of Latinx immigrants, resulting in distress, fear, and violence, like the directed attack of the 2018 El Paso shooting (Hutchinson \& Mallin, 2020). 
As such, the members within the group may feel resentful or complicit as a result of oppositional, hierarchical, and comparative derived responding and engaging in thoughts like "we didn't protest or riot when we were discriminated against," or "nobody spoke out for us," or "we need to focus on our own problems first." Unfortunately, these sentiments are not uncommon from Chinese and Latinx members regarding the mobilization of the Black Lives Matter movement (Meraji, 2016; Florido, 2016). These thoughts may be a product of confirmation bias, where individuals selectively attend to verbal behavior and events that support their position, and the erasure of Black advocacy in the media, such as the case of Patricia Okoumou's protest of the detention of migrant children in the United States (Aguilera, 2019) and the influence of Malcolm X on Asian-American activism (Kochiyama, 1994).

While the pain faced as individuals and groups as a whole is valid, raw, and real, it is dangerous to compare injustices as it begins to facilitate competition rather than cooperation. Historical contexts and conditions will vary for different racial groups, and non-Black people of color will naturally be more aware of the issues experienced by their own racial group. However, racial data suggest that police brutality is disproportionately higher towards Black people, resulting in significant damage and suffering of Black lives, and should be addressed as a public health crisis (Alang, 2017; Charles et al., 2015). To address a public health crisis, cooperation is critical over self-interest and needs to be accelerated (Goldberg, 2020).

\section{Mechanisms of Cooperation to Increase Solidarity}

There are mechanisms of cooperation required for evolutionary change: direct reciprocity, indirect reciprocity, network selection, and group selection (Novak, 2006). These mechanisms are also applicable in the context of culture change. Direct reciprocity is when two organisms have opportunities to cooperate with one another. One may cooperate now in the 
hopes that the other will also cooperate in return. This is akin to mutual occasions of reinforcement. Cooperation in this case can look like overt verbal behavior that empathizes and validates the other's feelings or overt verbal behavior or action that corrects racial inequity, like microaggressions or other forms of mistreatment. By cooperating initially, it may increase the likelihood that the other member will do the same. By engaging and interacting with members of other races, each member is likely to contact reinforcement from the other as a result of repeated encounters and can result in increased cooperation and thus benefit between members. Indirect reciprocity, on the other hand, does not mutually benefit both members. One member may be in a position to help the other, but there is no chance of repeated encounters or opportunities for the other to return the favor. After contacting direct reinforcement as a result of direct reciprocity, the act of cooperating itself may become a conditioned reinforcer. Therefore, indirect reciprocity is related to rule-governed behavior and conditioned reinforcement, underlying the cognitive aspects of antiracist actions. If an individual cooperates with another despite not receiving an immediate reinforcer, it can model desired behaviors to other members who engage in socialreferencing. Network reciprocity is the extension of cooperation to multiple members within a group, where the benefit of cooperating outweighs the risk or costs, much like a metacontingency. The outcome of both direct and indirect reciprocity can facilitate overall group gains and initiate a cultural shift. Finally, group selection is related to cultural selection. Cooperative group behavior as a whole is more likely to be more successful than a group of competitors or defectors. The reason being is that the payoff of cooperating is much higher overall and contributes much more to the group than those who simply do nothing to reciprocate. A group of defectors, in this case, can be conceptualized as individuals within a marginalized racial or ethnic group that does not offer solidarity or engage in overt acts of antiracism. 
The more likely members of non-Black racial and ethnic groups participate in acts of cooperation with Black activism, the more likely they will contact reinforcement. In doing so, these members will continue to cooperate, even without immediate socially-mediated reinforcement or benefit, which will contribute to antiracist cognition. By extending these actions to more members, inevitably like-minded groups will emerge, and ultimately, create a paradigm shift in cultural practices.

\section{Conclusion}

The marginalization of people of color may create a sense of invisibility, race-related stress, and even fear where members are less likely to self-advocate, participate, and even facilitate erasure of their own racial and ethnic identity (Franklin, 2016). These behaviors are likely a product of learned histories due to previous members modeling and engaging in the same behaviors across generations or even as a result of avoidance and escape from creating dissent in a white-dominant society. There is mounting literature directed to white individuals on practicing allyship and antiracism, which is warranted (Arnold, 2020; DiAngelo, 2018; Hagerman, 2018; Oluo, 2019; Tatum, 2017). Still, non-Black people of color, should not be excluded from those practices simply because they are people of color who have also suffered injustice and racism. Allyship requires one to also carry the weight and burden of underinvested and oppressed communities. Even if non-Black people of color do not fully understand the extent of the oppression of Black lives, they must make a concerted effort to listen and engage in behaviors that do not reinforce their biases on a day-by-day basis (Lamont, n.d.). By actively participating in acts of solidarity, non-Black people of color can facilitate their own cultural evolution. By engaging in repeated overt acts of support and cooperation, starting with the Black Lives Matter movement, all people of color are more likely to contact reinforcement for doing so, and per 
Novak's (2006) conceptualization, more likely to facilitate large scale change. By sharing our voices within our communities: our families, our work, our teachings, we are gradually shaping solidarity. That is the start of racial and ethnic equity that we are all striving toward.

\section{Examples of Cooperative Actions to Enact Today}

Direct reciprocity

- Participate in trainings and continuing education units offered by BIPOC.

- Seek mentorship from BIPOC from different racial or ethnic groups in supervisory or higher education roles in the field.

- Model antiracist language, and praise others for engaging in antiracist language in English and non-English languages.

Indirect reciprocity

- Provide mentorship within and outside one's cultural community.

- Participate in service, such as volunteering with organizations that support BIPOC.

- Incorporate the research and works of BIPOC in the field into coursework, trainings, or supervision in behavior analysis.

Network selection

- Join organizations in the field supporting BIPOC, such as Black Applied Behavior Analyst (BABA, 2019) and ABAI's Special Interest Groups like Culture and Diversity and Behaviorists for Social Responsibility (Association for Behavior Analysis International, n.d.).

- Facilitate small group discussions and meetings related to BIPOC perspectives and antiracist actions in the context of practice, ethics, and behavior analysis at large. 
- Voice concerns regarding the silencing of BIPOC.

- Leave groups, organizations, and companies not committed to antiracist actions.

- Support groups, organizations, and companies committed to antiracist actions via time, energy, and/or financial donations. 


\section{Compliance with Ethical Standards}

Funding: This study received no direct grants or funding.

Ethical Approval: This article does not contain any studies with human participants or animals performed by any of the authors. 
SOLIDARITY 14

\section{References}

Acevado, N. (2020, June 5). Latinos must confront "ingrained" anti-black racism amid George Floyd, some urge. NBC News. https:/www.nbcnews.com/news/latino/latinos-mustconfront-ingrained-anti-black-racism-amid-george-floyd-n1223696

Aguilera, J. (2019, July 2). This woman climbed the Statue of Liberty to protest family separation. One year later, she's wondering what's really changed. Time. https://ime.com/5615944/statue-of-liberty-climb-protest-family-separation/

Alang, S., McAlpine, D., McCreedy, E., \& Hardeman, R. (2017). Police brutality and black health: Setting the agenda for public health scholars. American Journal of Public Health, 107(5), 662-665. https://doi.org/10.2105/AJPH.2017.303691

Arnold, (2020). J. Raising our hands: How white women can stop avoiding hard conversations, start accepting responsibility, and find our place on the new frontlines. BenBella Books.

Association for Behavior Analysis International. (n.d.). Special Interest Groups.

https://www.abainternational.org/constituents/special-interests/special-interestgroups.aspx

Astramovich, R. L., \& Harris, K. R. (2007). Promoting self-advocacy among minority students in school counseling. Journal of Counseling \& Development, 85(3), 269-276. https://doi.org/10.1002/j.1556-6678.2007.tb00474.x

BBC News. (2020, March 19). Coronavirus: 'Racist attack' on Chinese in Southampton. BBC News. https://www.bbc.com/news/uk-england-hampshire-51961158

BABA. (2019). Mission. https://www.babainfo.org/

Booker, B. (2020, June 1). Violence erupts as outrage over George Floyd's death spills into a 
new week. National Public Radio. https://www.npr.org/2020/06/01/866472832/violenceescalates-as-protests-over-george-floyd-death-continue

Bowes, A., \& Sims, D. (2005). Advocacy for Black and minority ethnic communities: Understanding and expectations. British Journal of Social Work, 36(7), 1209-1225. https://doi.org/10.1093/bjsw/bch383

Charles, D., Himmelstein, K., Keenan, W., \& Barcelo, N. (2015). White coats for Black lives: Medical students responding to racism and police brutality. Journal of Urban Health: Bulletin of New York Academy of Medicine, 92(6), 1007-1010. https:/doi.org/10.1007/s11524-015-9993-9

Day, E. (2015, July 19). \#BlackLivesMatter: The birth of a new civil rights movement. The Guardian. https://www.theguardian.com/world/2015/jul/19/blacklivesmatter-birth-civilrights-movement

Dennison, A., Lund, E. M., Brodhead, M. T., Mejia, L., Armenta, A., \& Leal, J. (2019). Delivering home-supported applied behavior analysis therapies to culturally and linguistically diverse families. Behavior Analysis in Practice, 12, 887-889. https://doi.org/10.1007/s40617-019-00374-1

DiAngelo, R. (2018). White fragility: Why it's so hard for white people to talk about racism. Beacon Press.

Fazil, Q., Wallace, L. M., Singh, G., Ali, Z., \& Bywaters, P. (2004). Empowerment and advocacy: Reflections on action research with Bangladeshi and Pakistani families who have children with severe disabilities. Health and Social Care in the Community, 12(5), 389-397. https://doi.org/10.1111/j.1365-2524.2004.00508.x

Feagin, J. R. (2006). Systemic racism: A theory of oppression. Routledge. 
Florido, A. (2016, November 5). Latino activists ask, when should brown lives matter? National Public Radio. https://www.npr.org/2016/11/05/500810442/latino-activists-ask-whenshould-brown-lives-matter

Fong, E. H., Catagnus, R. M., Brodhead, M. T., Quigley, S., \& Field, S. (2016). Developing the cultural awareness skills of behavior analysts. Behavior Analysis in Practice, 9(1), 84-94. https://doi.org/10.1007/s40617-016-0111-6

Fong, E. H., Ficklin, S., \& Lee, H. Y. (2017). Increasing cultural understanding and diversity in applied behavior analysis. Behavior Analysis: Research and Practice, 17(2), 103. https://doi.org/10.1037/bar0000076

Franklin, A. J., Boyd-Franklin, N., \& Kelly, S. (2016). Racism and invisibility. Journal of Emotional Abuse, 6(2-3), 9-30. https://doi.org/10.1300/J135v06n02_02

Fuller, T. (2020, June 4). This curfew is meant to silence our voices. New York Times. https://www.nytimes.com/live/2020/george-floyd-protests-photos-videos-06-03

Goldberg, E. (2020, April 27). Regulatory cooperation to combat public health crises. Regulatory Review. https://www.theregreview.org/2020/04/27/golberg-regulatory-cooperationcombat-public-health-crises/

Garcia, S. E. (2020, June 17). Where did BIPOC come from? New York Times. https://www.nytimes.com/article/what-is-bipoc.html

Hagerman, M. A. (2018). White kids: Growing up with privilege in a racially divided America. NYU Press.

Hutchinson, B., \& Mallin, A. (2020, February 6). Alleged El Paso mass shooting suspect hit with federal hate-crime charges. $A B C$ News. https://abcnews.go.com/US/alleged-el-paso-massshooting-suspect-hit-federal/story?id=68807098 
Iyer, D. (2020, May 31). South Asians in the U.S. must support \#BlackLivesMatter, but first undo your own anti-Blackness. The Print. https://theprint.in/opinion/south-asians-in-theus-must-support-blacklivesmatter-but-first-undo-your-own-anti-blackness/432754/

Kendi, I. X. (2019). How to be an antiracist. One World.

Kochiyama, Y. (1994). The impact of Malcolm X on Asian-American politics and activism. In Jennings, J. (ed). Blacks, Latinos, and Asians in Urban America: Status and Prospects for Politics and Activism. Greenwood Publishing Group.

Kornack, J., Cernius, A., \& Persicke, A. (2019). The diversity is in the details: Unintentional language discrimination in the practice of applied behavior analysis. Behavior Analysis, 12, 879-886. https://doi.org/10.1007/s40617-019-00377-y

Lamont, A. (n.d.). Guide to allyship. Retrieved from https://guidetoallyship.com/\#what-is-anally

Lin, L., Stamm, K., \& Christidis, P. (2018). How diverse is the psychology workforce? Retrieved from https://www.apa.org/monitor/2018/02/datapoint

Matsuda, K., Garcia, Y., Catagnus, R., \& Brandt, J. A. (2020). Can behavior analysis help us understand and reduce racism? A review of the current literature. Behavior Analysis in Practice. https://doi.org/10.1007/s40617-020-00411-4

Meraji, S. M. (2016, July 27). A letter from young Asian-Americans to their families about Black Lives Matter. NPR. https://www.npr.org/sections/codeswitch/2016/07/27/487375314/a-letter-from-youngasian-americans-to-their-families-about-black-lives-matter

Merriam-Webster. (n.d.). Merriam-Webster.com dictionary. Retrieved June 7, 2020, from https://www.merriam-webster.com/dictionary/solidarity 
Nowak, M. A. (2006). Five rules for the evolution of cooperation. Science, 314(5805), 15601563. https://doi.org/10.1126/science.1133755

Oluo, I. (2019). So you want to talk about race. Seal Press.

Tatum, B. D. (2017). Why are all the Black kids sitting together in the cafeteria?: And other conversations about race. Basic Books.

Thompson, L. (2020, May 29). The police killing you probably didn't hear about this week. Mother Jones. https://www.motherjones.com/crime-justice/2020/05/tony-mcdadetallahassee-florida-police-shooting-death/

Wade, P. (2006). Afro-Latin studies. Reflections on the field. Latin American and Caribbean Ethnic Studies, 1(1), 105-124. https://doi.org/10.1080/17486830500509960

Watkins, A. (2020, June 3). In Brookyn, police use batons against protestors. New York Times. https://www.nytimes.com/live/2020/george-floyd-protests-photos-videos-06-03

Wilson, D. S. (2007). Evolution for everyone: How Darwin's theory can change the way we think about our lives. Delta.

Zarcone, J., Brodhead, M., \& Tarbox, J. (2019). Diversity and inclusion [Special section], Behavior Analysis in Practice, 12(4), 741-901. 